\title{
Article
}

\section{Crayfish Carapace Micro-powder (CCM): A Novel and Efficient Adsorbent for Heavy Metal Ion Removal from Wastewater}

\author{
Xiaodong Zheng, Bin Li *, Bo Zhu, Rui Kuang, Xuan Kuang, Baoli Xu and Meihu Ma \\ College of Food Science and Technology, Huazhong Agricultural University, Wuhan 430070, China; \\ E-Mails: zhxd1106@163.com (X.Z); brucezhubo5202003@yahoo.com.cn (B.Z.); \\ nonory_kuang@yahoo.com.cn (R.K.); kuangxuan512@yahoo.com.cn (X.K.); baoli84@qq.com (B.X.); \\ mameihuhn@yahoo.com.cn (M.M.)
}

* Author to whom correspondence should be addressed: E-Mail: libin343@yahoo.com.cn;

Tel.: +862-763-730-040; Fax: +862-787-282-966.

Received: 26 April 2010; in revised form: 10 May 2010 / Accepted: 27 May 2010 /

Published: 7 June 2010

\begin{abstract}
Crayfish carapace, a plentiful waste in China, was applied to remove divalent heavy metal ions - copper $(\mathrm{Cu})$, cadmium $(\mathrm{Cd})$, zinc $(\mathrm{Zn})$, and lead $(\mathrm{Pb})$ - from wastewater. The adsorption capacities of crayfish carapace micro-powder (CCM) for heavy metal ions were studied with adsorbent dosages ranging from $0.5-2.5 \mathrm{~g} / \mathrm{L}$ and with initial metal concentrations ranging from $50-250 \mathrm{mg} / \mathrm{L}$. CCM particle size, initial solution $\mathrm{pH}$ (from 2.5-6.5), temperature (from $25-65^{\circ} \mathrm{C}$ ) and calcium level (from 3.5-21.5\%) were also varied in batch mode. The results indicated that the adsorption capacity increases with both decreasing particle size and increasing calcium level of the crayfish carapace. The kinetic studies indicated that the adsorption could be complete within $2 \mathrm{~h}$, and that the data correlated with the pseudo-second-order model. CCM recorded maximum uptakes of $200,217.39,80$, and $322.58 \mathrm{mg} / \mathrm{g}$ for $\mathrm{Cu}, \mathrm{Cd}, \mathrm{Zn}$, and $\mathrm{Pb}$, respectively. The adsorption capacities and removal efficiencies of CCM for metal ions were three-times higher than those of chitin and chitosan extracted from the CCM.
\end{abstract}

Keywords: adsorption capacity; crayfish carapace; heavy metal ions; micro-powder; wastewater 


\section{Introduction}

Contamination of aqueous environments by toxic metals is a serious global problem due to their persistence, bioaccumulation, and bio-magnification through food webs [1]. Most of the heavy metals are highly toxic and non-biodegradable. In China, the maximum permissible concentrations of $\mathrm{Cu}(\mathrm{II})$, $\mathrm{Cd}(\mathrm{II}), \mathrm{Zn}(\mathrm{II})$ and $\mathrm{Pb}(\mathrm{II})$ are $2.0,0.1,5.0$ and $1.0 \mathrm{mg} / \mathrm{L}$, respectively [2]. Therefore, they must be removed from the waste effluents in order to meet increasingly stringent environmental quality standards. Numerous methods, including chemical precipitation, ion exchange, electrodeposition, membrane separation, and adsorption had been used to treat such effluents [3]. Of these methods, traditional chemical precipitation was the most economic, but it is inefficient. Ion exchange and reverse osmosis were generally effective, but had rather high maintenance and operational costs [4]. Adsorption, especially through the use of low-cost natural sorbents, is one of the few promising alternatives to remove toxic metals from aqueous environments.

Previous research demonstrated the possibility of using granular forms of activated carbon and chitin as adsorbents [5]. The use of biopolymers as adsorbents was an emerging technique for the treatment of industrial effluent containing toxic metals, and has been of great interest to researchers. A new development in recent years for the removal of heavy metal in wastewater is the use of chitin and chitosan as adsorbents. Chitin is a polysaccharide which is composed of $\beta(1-4)$ linked units of amino sugar $\mathrm{N}$-acetyl-glucosamine. It is extracted and isolated by treating native crustacean shells of crabs, shrimps, and lobsters, etc., with strong acids for decalcification and with strong bases for deproteinization. Chitosan is the deacetylated form of chitin with a high content of functional amine groups $\left(-\mathrm{NH}_{2}\right)$ [6,7]. Numerous studies have shown that chitin and chitosan have high binding capacities for many heavy metals in aqueous solutions [8]. Chemically modified chitosans were prepared in order to improve pore size, mechanical strength, chemical stability, hydrophilicity, and biocompatibility, which led to the increase of adsorption capacities [9]. However, the costs of these former adsorbents were rather high and thus, they were not satisfactory for solving practical problems. Therefore, more effective and low-cost alternatives are urgently required.

Recently, naturally abundant biomass, industrial/agricultural by-products, and seafood wastes were used effectively for the adsorption of metals. Crayfish carapace also showed the potential to remove toxic metals. Volesky et al. [10] found that the properties needed to achieve optimum biosorption performance include structural stability, porosity, large surface areas, hydrophilicity, and metal binding functional groups. Carapace, as a low cost adsorbent, has such construction features as described above. The amine and sulfur functional groups of chitin and proteins provide donor ligands and chelation sites for adsorption [11]. In addition, crayfish carapace contains large amounts of calcium carbonate, which is important for removing metal ions.

Until present, crayfish carapace was discarded as waste when processed into headless carapace-by products. The peeling process, which involves removal of the carapace from the tail of the crayfish, increased the amount of waste production. Such wastes produced at large-scale processing facilities served as a reliable and regular source of potential adsorbing material. The crayfish carapace was chosen as the subject for this study due to their wide geographic distribution, commercial availability, and relative abundance in the world. Few researches reported the adsorption property of crayfish carapace. In this paper, we utilized a novel treatment method involving a high-frequency, oscillatory 
type ball mill to crush the crayfish carapace. The equilibrium of adsorption and the ideal experimental conditions were studied in detail. Langmuir and Freundlich equations were used to fit the adsorption isotherms. The adsorption rate was determined quantitatively and fitted by the first- and second-order kinetic model. This information will be useful for further applications of system design in the treatment of practical waste effluents.

\section{Materials and Methods}

\subsection{Materials}

Crayfish carapaces were collected from the fair trade market of Huazhong Agricultural University in Wuhan, China. Carapaces were separated from the entire shell, washed using running water, and then dried at $105^{\circ} \mathrm{C}$ for $2 \mathrm{~h}$ without any further chemical treatments. The dried carapaces were crushed with a ball mill for 20,40,60, 80, and $100 \mathrm{~min}$, respectively. Crayfish carapaces with varying degrees of decalcification were obtained by immersing the carapaces in different volumes (120, 180, and $240 \mathrm{~mL}$ ) of hydrochloric acid [12]. When carapaces touched hydrochloric acid, there came the presence of a large number of air bubbles resulting from the reaction between hydrochloric acid and carbonate calcium in the carapace. The carapaces were kept in the hydrochloric acid solution for $2 \mathrm{~h}$ after air bubbles disappeared. Then the powder was rinsed with distilled water until the wash-solution $\mathrm{pH}$ was close to that of distilled water. The residue was dried at $50{ }^{\circ} \mathrm{C}$ and ground with an agate mortar. The extracts of crayfish carapace, chitin, and two chitosans with deacetylation degrees of 70.9 and $88.6 \%$, respectively, were prepared by the methods of decalcification and deacetylation described previously [13]. The obtained samples were milled for $60 \mathrm{~min}$.

Stock solutions of metal ions were prepared with highly purified metal powder. These stocks were then diluted to standard solutions of appropriate concentrations. Highly purified water was obtained by deionization and filtration with a Millipore purification apparatus. Mimic liquid wastes were prepared by dissolving solid $\mathrm{CuSO}_{4} \cdot 5 \mathrm{H}_{2} \mathrm{O}, \mathrm{CdSO}_{4} \cdot 8 \mathrm{H}_{2} \mathrm{O}, \mathrm{Pb}\left(\mathrm{NO}_{3}\right)_{2}$, and $\mathrm{ZnSO}_{4} \cdot 7 \mathrm{H}_{2} \mathrm{O}$ in deionized water, respectively. The $\mathrm{pH}$ values of the solution were measured using a $\mathrm{pH}$ meter (MODEL818 type, American Orion Company) and adjusted by using $1 \mathrm{M} \mathrm{HCl}$ and $0.5 \mathrm{M} \mathrm{CH}_{3} \mathrm{COONa}$.

\subsection{Adsorption Experiments}

For adsorption studies, $0.02 \mathrm{~g} \mathrm{CCM}$ (ball-milled for $60 \mathrm{~min}$ ) was incubated with $20 \mathrm{~mL}$ of metal ion solution in a $30 \mathrm{~mL}$ plastic centrifuge tube. The tubes were then placed in a constant-temperature shaker at $180 \mathrm{rpm}$ and samples were taken at regular time intervals. After adsorption, the samples were centrifuged at 3,000 rpm for $10 \mathrm{~min}$. The metal content in the supernatant was determined using a flame atomic absorption spectrophotometer (Aa240fs, American Varian Company). Each type of batch experiment was conducted in triplicate and the mean values were reported in this study. Adsorption capacities of metal ions were determined using the following equation:

$$
Q=\frac{\left(\mathrm{C}_{0}-C_{e}\right)}{\mathrm{C}_{1}}
$$


where $Q$ is the adsorption capacity achieved in a given experiment $(\mathrm{mg} / \mathrm{g}) ; \mathrm{C}_{\mathrm{o}}$ and $C_{e}$ are the initial and equilibrium metal concentrations in the solution $(\mathrm{mg} / \mathrm{L})$, respectively; and $\mathrm{C}_{1}$ is the concentration of adsorbent $(\mathrm{g} / \mathrm{L})$.

The removal efficiency of metal ions was calculated using the following formula:

$$
X=\frac{Q}{C_{o} \times V} \times 100 \%
$$

where $\mathrm{X}$ is removal efficiency $(\%) ; \mathrm{C}_{\mathrm{O}}$ is the initial concentration in solution $(\mathrm{mg} / \mathrm{L}) ; \mathrm{V}$ is the solution volume (L); and $Q$ is the metal uptake $(\mathrm{mg} / \mathrm{g})$.

\subsection{Determination of Calcium Level}

Crayfish carapaces $(0.5 \mathrm{~g})$ were mixed with $3 \mathrm{~mL}$ perchloric acid and $12 \mathrm{~mL}$ concentrated nitric acid in a glass flask. The contents were heated gently on a hot plate until no black smoke was found in the digested flask. After cooling, digested samples were diluted using deionized water and put into small tubes. The solutions were stored in a refrigerator until ready for determination [14]. The content of metal ions and calcium ions in the supernatant were determined using flame atomic absorption spectrophotometry (Aa240fs, Varian Company, American).

\section{Results and Discussion}

\subsection{Effect of Adsorbent Dosages}

The influence of dosage of CCM (from $0.5-2.0 \mathrm{~g} / \mathrm{L}$ ) on copper $(\mathrm{Cu})$, cadmium $(\mathrm{Cd})$, zinc $(\mathrm{Zn})$, and lead $(\mathrm{Pb})$ adsorption were examined (Figure 1a). Under certain conditions, with the concentration of metal ions and other factors constant, the adsorption capacities decreased with increasing adsorbent dosage [15]. Nevertheless, the removal efficiency increased with increasing adsorbent dosage because of the increase in surface area of the adsorbent, which in turn increased the number of binding sites (Figure 1b). After the dosage reached $1.0 \mathrm{~g} / \mathrm{L}$, removal efficiency of copper, cadmium, and lead reached the maximum, while removal efficiency of zinc reached the maximum at $1.5 \mathrm{~g} / \mathrm{L}$. The adsorption capacity and the removal efficiency are very important properties for an adsorbent. Based on these results, the adsorbent dosage of $1 \mathrm{~g} / \mathrm{L}$ was selected for further studies as the best dosage for good adsorption results.

\subsection{Adsorption Kinetics}

The adsorption kinetic was influenced by various factors, including initial metal ion concentration, amount of adsorbent, $\mathrm{pH}$, and temperature. The initial metal ion concentration was one of the most important factors. The factor determines the equilibrium concentration, as well as the uptake rates of metal ions and the kinetic characteristics [16]. For the purpose of further studies, varying initial time conditions are shown in Figure 2. 
Figure 1. Influence of adsorbent dosage of CCM on the adsorption capacities (a) and removal efficiency (b) of the four heavy metal ions copper $(\mathrm{Cu})$, cadmium $(\mathrm{Cd})$, zinc $(\mathrm{Zn})$, and lead $(\mathrm{Pb})$. Initial metal concentration $=100 \mathrm{ppm}$; agitation speed $=180 \mathrm{rpm}$; initial $\mathrm{pH}=5.5$; temperature $=25^{\circ} \mathrm{C}$; equilibrium time $=2 \mathrm{~h}$ ).
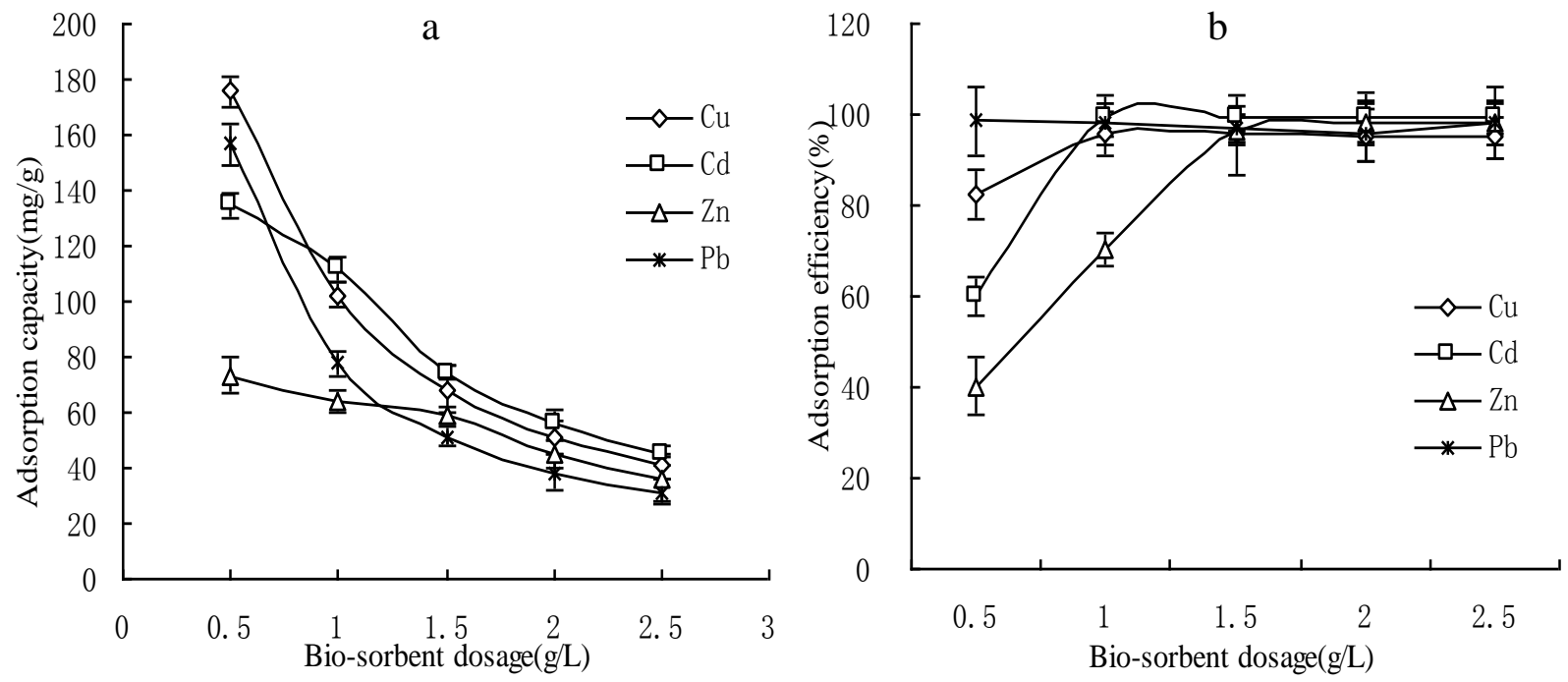

Figure 2. Influence of time on adsorption capacities of CCM for metal ions (initial metal solution concentration $=100 \mathrm{ppm}$; agitation speed $=180 \mathrm{rpm}$; temperature $=25{ }^{\circ} \mathrm{C}$; dosage $=1.0 \mathrm{~g} / \mathrm{L}$; initial $\mathrm{pH}=5.5)$.

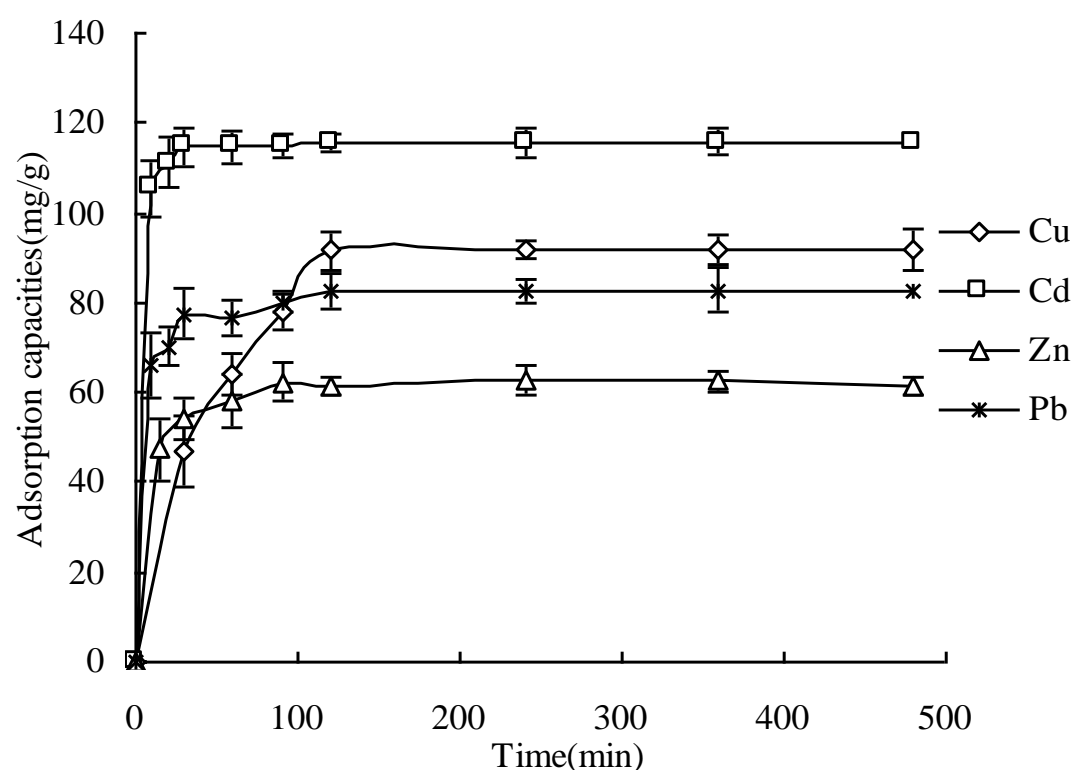

Metal ions removed by carapace were evaluated at contact times ranging from $15 \mathrm{~min}$ to $480 \mathrm{~min}$. Figure 2 showed the time profiles of metal ion adsorption on the CCM. The adsorption processes of $\mathrm{Cu}$, $\mathrm{Cd}, \mathrm{Zn}$, and $\mathrm{Pb}$ reached the adsorption equilibrium within $120 \mathrm{~min}, 30 \mathrm{~min}, 90 \mathrm{~min}$, and $120 \mathrm{~min}$, respectively. These times were all close to the equilibrium time of the hollow fiber, which was a satisfactory modified adsorbent, and finally reached the adsorption equilibrium after 70 min [7]. All 
the adsorption experiments of these metal ions reached equilibrium within $2 \mathrm{~h}$. Consequently, the adsorption time of $2 \mathrm{~h}$ was optimal for further studies.

In order to examine the mechanism controlling the adsorption processes, pseudo first-order and pseudo second-order kinetic models were used to fit the experimental data and determine whether the adsorption process was dominated by a physical or a chemical mechanism. The linear forms of the pseudo first-order and pseudo second-order models are given in Equations (3) and (4), respectively $[17,18]$ :

$$
\log \left(Q_{e}-Q_{t}\right)=\log \left(Q_{e}\right)-\frac{k_{1}}{2.303} t
$$

where $\mathrm{Q}_{\mathrm{e}}$ and $\mathrm{Q}_{\mathrm{t}}$ are the amounts of metal ion adsorbed on adsorbent $(\mathrm{mg} / \mathrm{g})$ at equilibrium and at time $t$, respectively. $\mathrm{k}_{1}$ is the rate constant of first-order adsorption $\left(\mathrm{min}^{-1}\right)$.

$$
\frac{t}{Q_{t}}=\frac{1}{k_{2} Q_{e}^{2}}+\frac{t}{Q_{e}}
$$

where $\mathrm{k}_{2}$ is the rate constant of second-order adsorption $\left(\mathrm{g} / \mathrm{mg} \min ^{-1}\right)$. The straight-line plots of $\mathrm{t} / \mathrm{Q}_{\mathrm{t}}$ against $\mathrm{t}$ had been tested to obtain rate parameters and it suggested the applicability of this kinetic model to fit the experimental data.

The linear relationships and correlation coefficient of the two rate equations are shown in Table 1. The $\mathrm{R}^{2}$ for the second-order equation of $\mathrm{Cu}, \mathrm{Cd}, \mathrm{Zn}$, and $\mathrm{Pb}$ were all much higher than the $\mathrm{R}^{2}$ values in the first-order equation. Hence, the data suggests that the second-order equation could describe the adsorption process better. Rosa et al. [19] explained that the adsorption of the second-order reaction passes through several stages involving the transport of the adsorbate from the aqueous phase to the adsorbent surface and diffusion of the adsorbate into the interior of the adsorbent pores, which is a slow process.

Table 1. Correlation coefficient and correlative parameters of the two rate equations.

\begin{tabular}{ccccccccc}
\hline & \multicolumn{2}{c}{ Pseudo first-order equation } & & \multicolumn{3}{c}{ Pseudo second-order equation } \\
\cline { 2 - 4 } Ions & $\mathbf{Q}_{\mathbf{e}}(\mathbf{m g} / \mathbf{g})$ & $\mathbf{k}_{\mathbf{1}}$ & $\mathbf{R}^{\mathbf{2}}$ & & $\mathbf{Q}_{\mathbf{e}}(\mathbf{m g} / \mathbf{g})$ & $\mathbf{k}_{\mathbf{2}}$ & $\mathbf{R}^{\mathbf{2}}$ \\
\hline $\mathrm{Cu}$ & 93.045 & 0.0294 & 0.8916 & & 106.383 & 0.0025 & 0.9651 \\
$\mathrm{Cd}$ & 101.3705 & 0.0469 & 0.8622 & & 116.2791 & 0.0881 & 0.9514 \\
$\mathrm{Zn}$ & 61.8682 & 0.0365 & 0.8077 & & 63.6943 & 0.0302 & 0.9796 \\
$\mathrm{~Pb}$ & 77.2632 & 0.0415 & 0.9139 & & 82.6445 & 0.0452 & 0.9314 \\
\hline
\end{tabular}

\subsection{Effect of CCM Size}

The particle size distributions of CCM when milled for different time durations are shown in Figure 3. The diameter of CCM particles existed in a wide range (83.04-997.94 $\mu \mathrm{m})$ when the ball-milled time was $20 \mathrm{~min}$. With increasing ball-milled time, the particle size distribution narrowed; when the samples were crushed by ball-mill for a duration of $100 \mathrm{~min}$, the diameter of particles was in the range of 0.04-56.87 $\mu \mathrm{m}$. The volume distribution of CCM showed a single peak within the shorter ball-milled time. With the increase of time, the distribution changed gradually. With a ball-mill duration of $100 \mathrm{~min}$, it showed the typical three populations with peak values of $3.10 \mu \mathrm{m}, 9.54 \mu \mathrm{m}$ 
and $43.80 \mu \mathrm{m}$. After $60 \mathrm{~min}$ of ball-milled, the particle size decreasing rate became smaller; this predicts that the micronization action became no longer significant. Thus, extending the ball-milled time to decrease the particle size beyond this point would not be beneficial. In addition, the mean values of all the samples were $416.0,216.8,151.3,82.36,31.74$, and $12.95 \mu \mathrm{m}$, after $0,20,40,60,80$, and 100 min of ball-milled time, respectively.

Figure 3. The effect of the ball-milled time on the mean size of crayfish carapace particles. The duration of ball-milled time is $0 \mathrm{~min}$ (a), $20 \mathrm{~min}$ (b), $40 \mathrm{~min}$ (c), $60 \mathrm{~min}$ (d), $80 \mathrm{~min}$ (e), and 100 min (f). The pink line means cumulative particle size distribution of CCM and the blue shaded regions means particle size distributions of CCM.
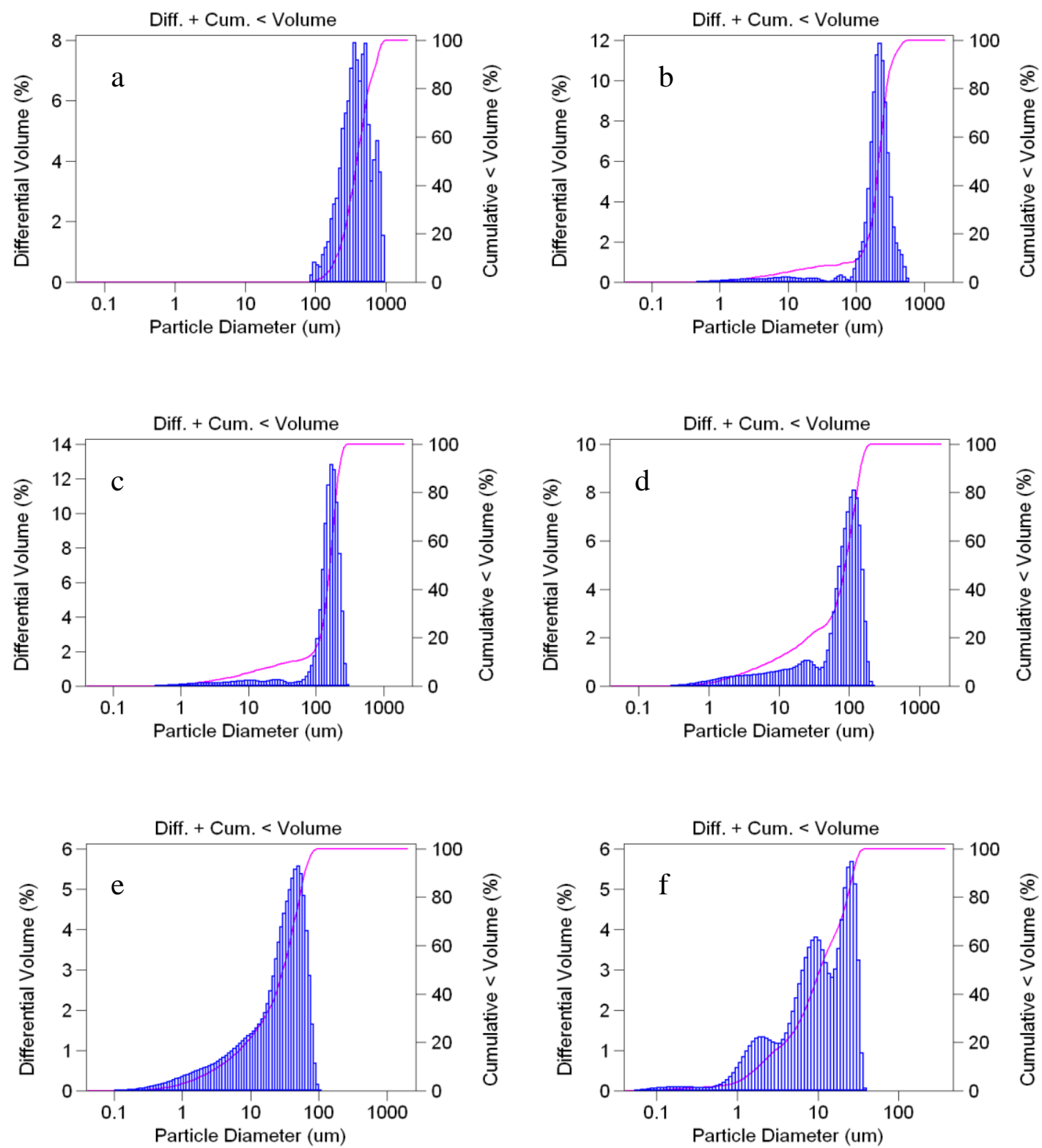

It can be observed in Figure 4 that the adsorption capacities for the metal ions gradually increased with decreasing carapace powder size. As a whole, the adsorption capacities of the four metal ions increased 2-4 times when the particle size was reduced from $>198 \mu \mathrm{m}$ to $<35 \mu \mathrm{m}$. The CCM had better adsorption capacity because small particles provide a larger surface area. Rojasa et al. [20] also 
indicated that adsorbents with low porosity and particles of small diameter were expected to develop high adsorption capacities. The decreasing particle size leads to increased adsorbent surface area, thus more active sites are available. $\mathrm{Q}_{\mathrm{i}}$ et al. [21] found that the capacity of chitosan nanoparticles became much higher when the mean size decreased. All these findings support the observation that the smaller particulate size was, the better the adsorption capacity of the powder.

Figure 4. Influence of CCM size on adsorption capacities for heavy metal ions (initial metal concentration $=100 \mathrm{ppm}$; agitation speed $=180 \mathrm{rpm}$; equilibrium time $=2 \mathrm{~h}$; temperature $=25^{\circ} \mathrm{C}$; dosage $=1.0 \mathrm{~g} / \mathrm{L}$; initial $\mathrm{pH}=5.5$ ).

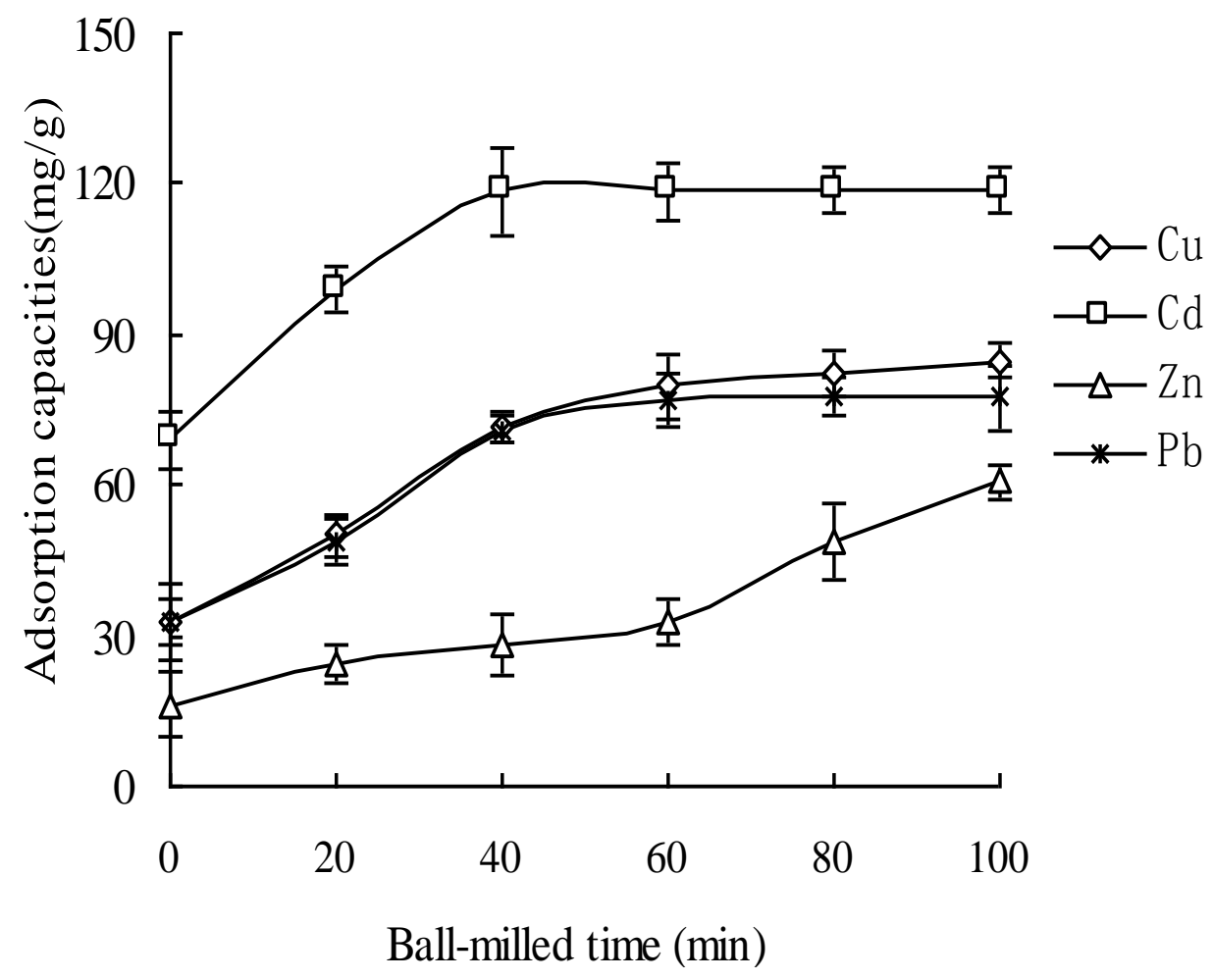

\subsection{Effect of Solution $p H$}

The influence of initial solution $\mathrm{pH}$ on metal ion adsorption was examined by varying the $\mathrm{pH}$ from 2.5 to 6.5 . When the $\mathrm{pH}$ exceeded 6.5, the solution became turbid or precipitated. Adsorption capacities were highly dependent upon the $\mathrm{pH}$ values in the metal ion solution (Figure 5). As the $\mathrm{pH}$ was increased from 2.5 to 3.5, the adsorption capacities for $\mathrm{Cu}, \mathrm{Cd}$, and $\mathrm{Pb}$ increased slowly. In the $\mathrm{pH}$ region from 4.5 to 6.5 , the amounts of the aforementioned adsorbed metal ions were almost constant. In contrast, the adsorption capacities of zinc increased with increasing $\mathrm{pH}$ value up to 6.5. Lu et al. [22] found that the optimal initial $\mathrm{pH}$ of $\mathrm{Zn}^{2+}$ solution for adsorption by $\mathrm{CCM}$ was near neutral. This was in accordance with our experimental trend. Under acidic conditions, the concentration of protons exceeded and out-competed metal ions for occupation of the binding sites on the crayfish carapace, leaving metal ions free in solution. In addition, the final solutions $\mathrm{pH}$ values of $\mathrm{Cu}, \mathrm{Cd}, \mathrm{Pb}$ and $\mathrm{Zn}$ after adsorption were $8.16,8.27,8.33,8.64$ and 8.79 , respectively. This change was also beneficial for wastewater discharge. 
Figure 5. Influence of initial solution $\mathrm{pH}$ on adsorption capacities of CCM for heavy metal ions (initial metal concentration $=100 \mathrm{ppm}$; agitation speed $=180 \mathrm{rpm}$; equilibrium time $=2 \mathrm{~h}$; temperature $=25^{\circ} \mathrm{C}$ ).

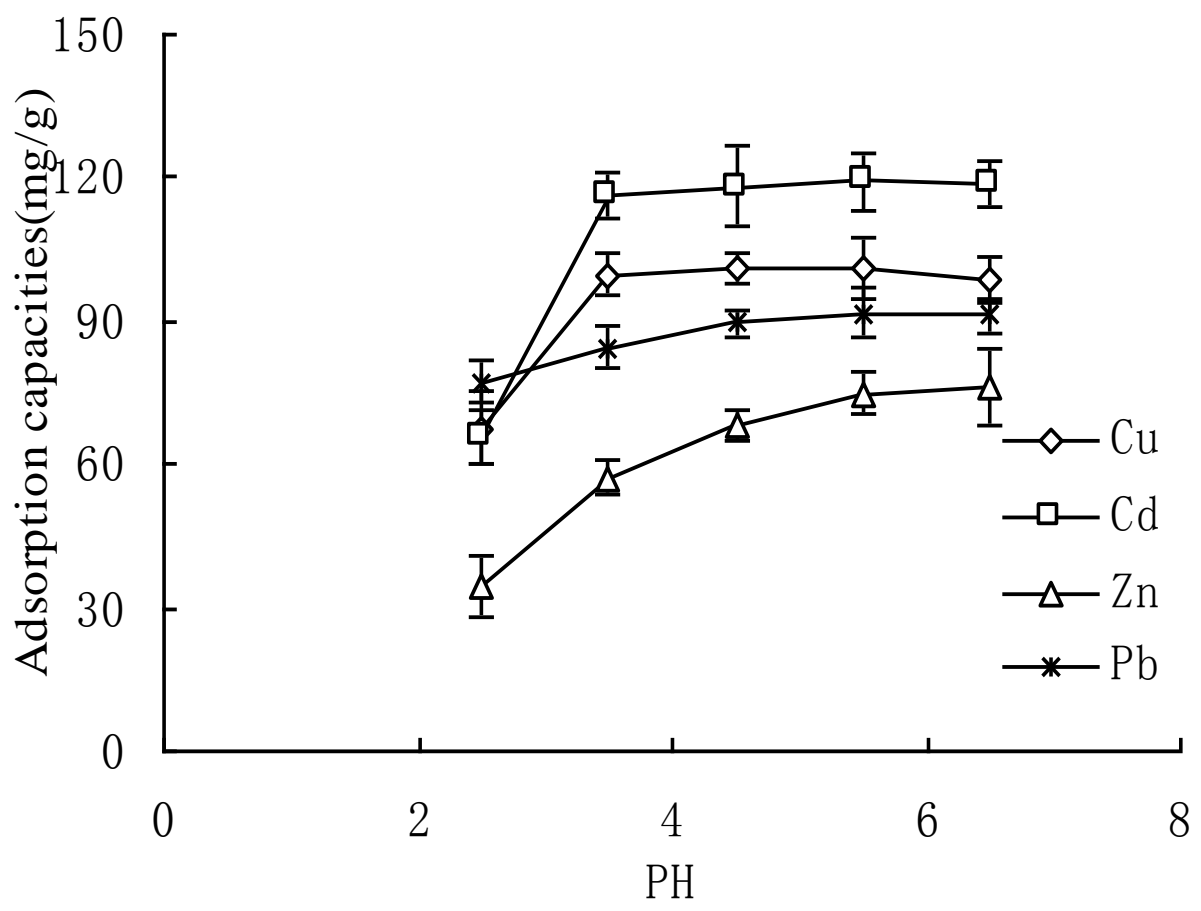

\subsection{Thermodynamic Property of Adsorption}

The experimental temperature was controlled from $25{ }^{\circ} \mathrm{C}$ to $65{ }^{\circ} \mathrm{C}$ in this study. Figure 6 shows the relationship between temperature and adsorption capacities. With increasing temperature, the adsorption capacity for $\mathrm{Cu}$ moderately decreased, while the capacities for $\mathrm{Cd}$ and $\mathrm{Zn}$ appreciably increased. In addition, when the temperature increased, the adsorption capacity of $\mathrm{Pb}$ decreased firstly from $25{ }^{\circ} \mathrm{C}$ to $45^{\circ} \mathrm{C}$ and finally increased from $45{ }^{\circ} \mathrm{C}$ to $65{ }^{\circ} \mathrm{C}$. In other words, the capacity changed irregularly.

The influence of temperature on metal ion adsorption was examined on the basis of the Clausius-Clapeyron Equation [23]:

$$
\operatorname{LnC}_{e}=\frac{\Delta H}{R \times T}+K
$$

where $\mathrm{C}_{\mathrm{e}}$ is the equilibrium metal ion concentration in the solution $(\mathrm{mg} / \mathrm{L}) ; \mathrm{R}$ is the gas constant $(8.314 \mathrm{~J} / \mathrm{K} \cdot \mathrm{mol})$; $\mathrm{T}$ is Kelvin temperature; $\Delta \mathrm{H}$ is enthalpy of adsorption; and $\mathrm{K}$ is the general integration constant. 
Figure 6. Influence of solution temperature on the adsorption capacities of CCM for the four heavy metal ions (initial metal concentration $=100 \mathrm{ppm}$; agitation speed $=180 \mathrm{rpm}$; equilibrium time $=2 \mathrm{~h}$; dosage $=1.0 \mathrm{~g} / \mathrm{L}$; initial $\mathrm{pH}=5.5$ ).

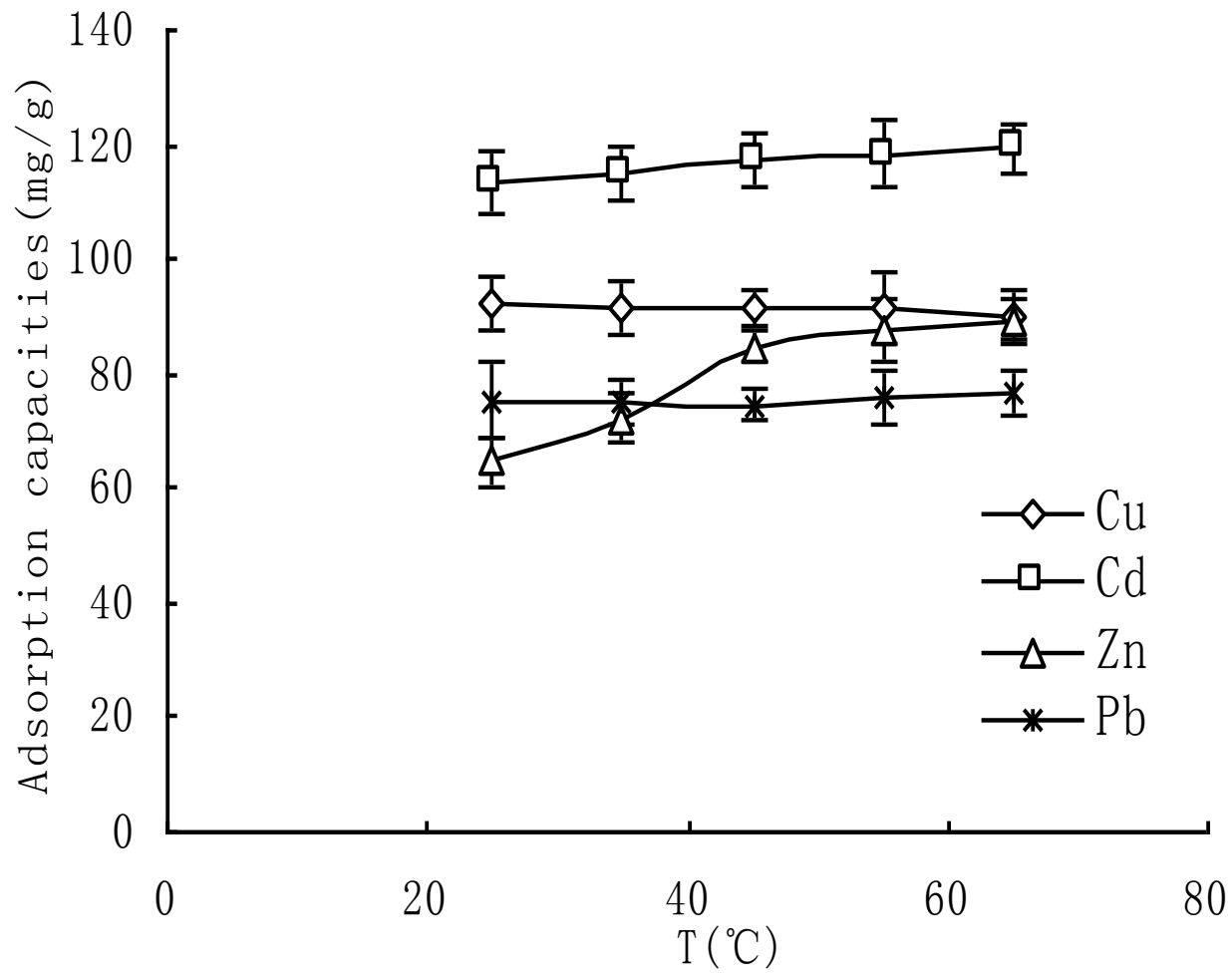

The equation was linearized and plotted, $\operatorname{lnC}_{\mathrm{e}}$ versus $(1 / \mathrm{T})$, so as to calculate the enthalpy of adsorption according to the slope of the straight line. The correlation coefficient and correlative parameters are shown in Table 2. The values of the thermodynamic parameters and adsorption enthalpy could directly reflect the property of adsorption capacity [23]. The adsorption enthalpy of $\mathrm{Cu}$ was of a negative value. The adsorption process was therefore exothermal, making decreasing temperature advantageous. In contrast, the enthalpies of $\mathrm{Cd}$ and $\mathrm{Zn}$ were positive in value. Hence, decreasing temperature was disadvantageous for adsorption. The relationship between the adsorption capacity of $\mathrm{Pb}$ and temperature was not linear. Thus, lead adsorption was not dependent upon the temperature.

Table 2. Correlation coefficient $(\Delta \mathrm{H})$ and correlative parameter $\left(\mathrm{R}^{2}\right)$ of adsorption of the four metal ions.

\begin{tabular}{ccc}
\hline Metal ions & $\Delta \mathbf{H}(\mathbf{K J} \mathbf{J})$ & $\mathbf{R}^{\mathbf{2}}$ \\
\hline $\mathrm{Cu}$ & $-2,036.26$ & 0.9497 \\
$\mathrm{Cd}$ & $4,223.51$ & 0.9592 \\
$\mathrm{Zn}$ & $54,006.08$ & 0.9963 \\
$\mathrm{~Pb}$ & - & -
\end{tabular}




\subsection{Adsorption Isotherm}

Figure 7 shows the relationship between the amount of metal ions adsorbed on the crayfish carapace surface at equilibrium $\left(\mathrm{Q}_{\mathrm{e}}\right)$ and the equilibrium concentration of these metal ions in the aqueous phase $\left(\mathrm{C}_{\mathrm{e}}\right)$. It was observed that the amount of metal ions on the adsorbent surface increased with the concentration of metal ions in solution, resulting in surface saturation at high concentrations. In this study, it was also found that the higher the initial metal ion concentration, the lower the removal efficiency. This relationship shows that the adsorption capacities increased with the equilibrium concentration of metal ions in solution, until reaching adsorbent saturation. As a whole, the adsorption capacities of $\mathrm{Zn}$ increased slowly with the equilibrium concentration of these metal ions in the aqueous phase. In contrast, the adsorption capacities of the other metal ions increased sharply.

Figure 7. Adsorption isotherms of metal ions on crayfish carapace (agitation speed = $180 \mathrm{rpm}$; equilibrium time $=2 \mathrm{~h}$; temperature $=25^{\circ} \mathrm{C}$; initial $\mathrm{pH}=5.5$; dosage $=1.0 \mathrm{~g} / \mathrm{L}$ ).

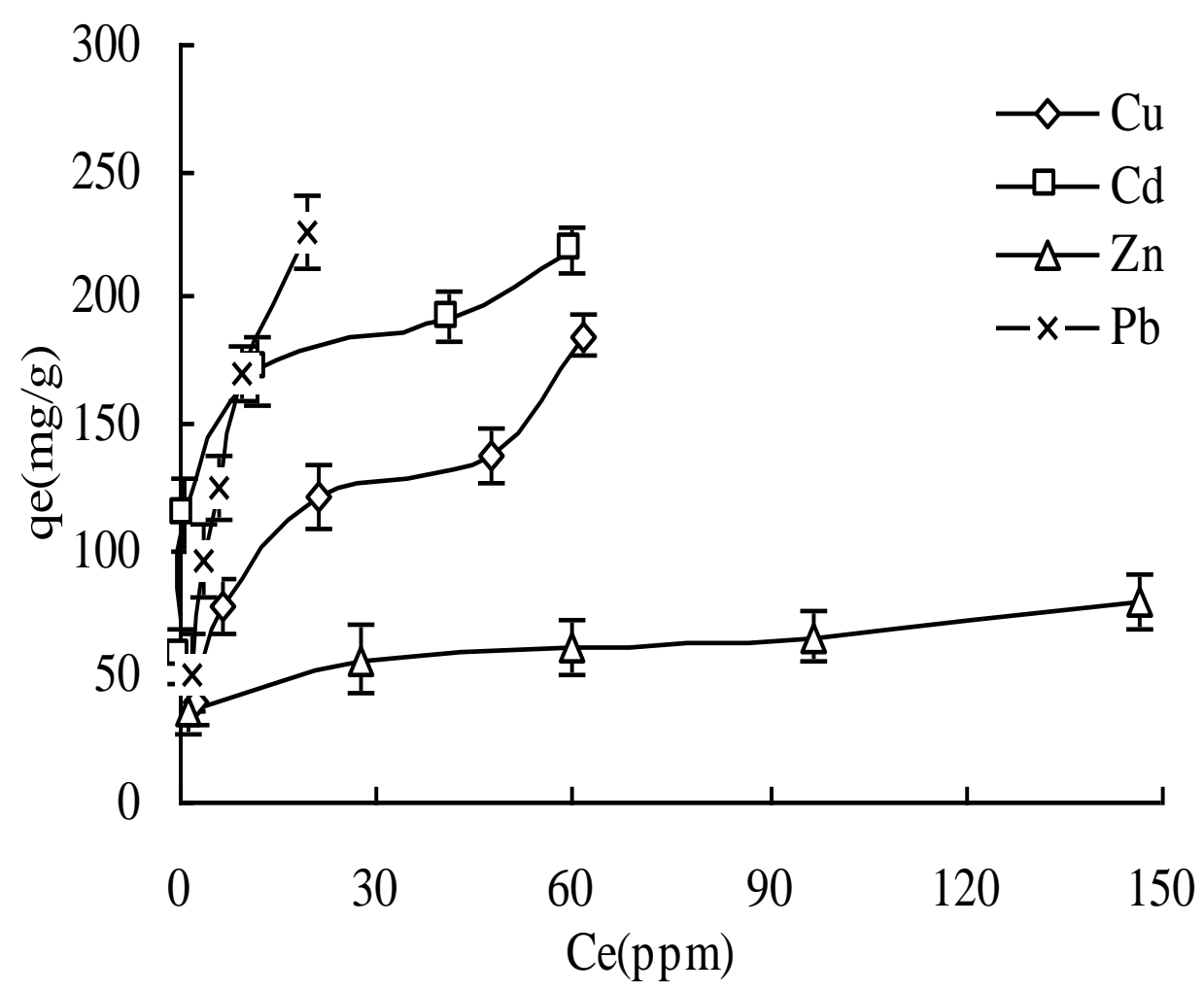

The adsorption capacity of metal ions at equilibrium and the equilibrium concentration of these metal ions were fitted with the Langmuir and Freundlich isotherm models. The Langmuir model assumes that the adsorbent surface has sites of identical energy and that each adsorbate molecule is assumed to be located at a single site. Hence, it predicts the formation of a monolayer of the adsorbate on the adsorbent surface. On the other hand, the Freundlich model does not restrict itself to a monolayer of adsorbent covering [24,25]. The isotherm model giving the best fit to the measured data was selected for the determination of the parameters. The Langmuir and Freundlich equations are describe in Equations (6) and (7), respectively: 


$$
\frac{C_{e}}{Q_{e}}=\frac{C_{e}}{Q_{m}}+\frac{1}{Q_{m} b}
$$

where $\mathrm{Q}_{\mathrm{m}}$ and $\mathrm{C}_{\mathrm{e}}$ are the maximum adsorbed amount (mg/g) and the concentration of each component at equilibrium (ppm), respectively. $b$ is the heterogeneity parameter for each component, and is dimensionless.

$$
\operatorname{Ln}\left(Q_{e}\right)=\operatorname{Ln}\left(K_{f}\right)+\frac{1}{n} \operatorname{Ln}\left(C_{e}\right)
$$

In this expression, $\mathrm{K}_{\mathrm{f}}$ and $\mathrm{n}$ are Freundlich constants indicating adsorption capacities and intensity, respectively. $\mathrm{K}_{\mathrm{f}}$ and $\mathrm{n}$ can be determined from a linear plot of $\ln \mathrm{Q}_{\mathrm{e}}$ against $\ln _{\mathrm{e}}$.

The calculated results of the Langmuir and Freundlich isotherm constants are given in Table 3. The correlation coefficient values $\left(\mathrm{R}^{2}\right)$ of the Langmuir model were obviously higher than Freundlich's, and their adsorption capacities $\left(\mathrm{Q}_{\mathrm{m}}\right)$ were much more rational and practical. It was recorded that the adsorption maximum of $\mathrm{Cu}, \mathrm{Cd}, \mathrm{Zn}$, and $\mathrm{Pb}$ were 200, 217.39, 80 and $322.58 \mathrm{mg} / \mathrm{g}$, respectively. For the Langmuir equation, the $\mathrm{R}^{2}$ of the four metal ions all exceeded 0.97 .

Table 3. Adsorption isotherm constants and correlation coefficients of two models.

\begin{tabular}{cccccccc}
\hline & \multicolumn{3}{c}{ Langmuir } & & \multicolumn{3}{c}{ Freundlich } \\
\cline { 2 - 3 } \cline { 6 - 7 } Ion & $\mathbf{2}(\mathbf{m g} / \mathbf{g})$ & $\begin{array}{c}\mathbf{B} \\
(\mathbf{m L} / \mathbf{m g})\end{array}$ & $\mathbf{R}^{\mathbf{2}}$ & & $\mathbf{K}_{\mathbf{f}}(\mathbf{m g} / \mathbf{g})$ & $\mathbf{n}$ & $\mathbf{R}^{\mathbf{2}}$ \\
\hline $\mathrm{Cu}$ & 200 & 0.0852 & 0.9772 & & 30.481 & 2.3207 & 0.9683 \\
$\mathrm{Cd}$ & 217.39 & 0.6053 & 0.9924 & & 99.315 & 5.0428 & 0.9427 \\
$\mathrm{Zn}$ & 80 & 0.0945 & 0.9722 & & 34.519 & 6.6445 & 0.9461 \\
$\mathrm{~Pb}$ & 322.58 & 0.1148 & 0.9992 & & 42.06 & 1.6841 & 0.9822 \\
\hline
\end{tabular}

\subsection{Effect of Calcium Level of CCM}

In this study, in order to confirm that the crayfish carapace has a micro-porous structure after being removed from an inorganic matrix, various carapace products of different calcium levels were prepared. Nevertheless, such porosities were not observed in scanning electron microscope (SEM) images. It was supposed that the pores would be too big to endure the force of a ball mill; they would have fractured and disappeared. This had already been confirmed in a previous investigation [27], where they found that the pore size in the crayfish shell was around 15-20 $\mu \mathrm{m}$ after decalcification. The maximum adsorption capacities of crayfish carapace with different calcium levels for metal ions are shown in Figure 8. Obviously, the capacities increased with increasing calcium level. Raw CCM, with a calcium level at the maximum (21.5\%), owned the highest adsorption capacities and removal efficiencies.

A few previous studies demonstrated that the calcium ion of CCM exchanged with metal ions. After removing part of the calcium carbonate, less calcium ions were exchanged with metal ions [28]. Former studies confirmed that the calcium carbonate in the CCM dissolved quickly under the acidic conditions, and that dissociated carbonate ions caused the formation of precipitates with metal ions on the surface of the CCM [8]. In addition, calcium carbonate in CCM had different crystal forms and usually was at a high-energy state in the biomineralization material. When the calcium was removed using hydrochloric acid, the pristine crystal structure was destroyed, and a large number of micropores 
disappeared. Hence, the CCM after decalcification could not effectively adsorb metal ions anymore. These problems need investigation in future studies.

Figure 8. Adsorption capacities of metal ions on crayfish carapace with different calcium levels (initial metal concentration $=100 \mathrm{ppm} ;$ agitation speed $=180 \mathrm{rpm}$; equilibrium time $=2 \mathrm{~h}$; temperature $=25^{\circ} \mathrm{C}$; initial $\mathrm{pH}=5.5$; dosage $=1.0 \mathrm{~g} / \mathrm{L}$ ).

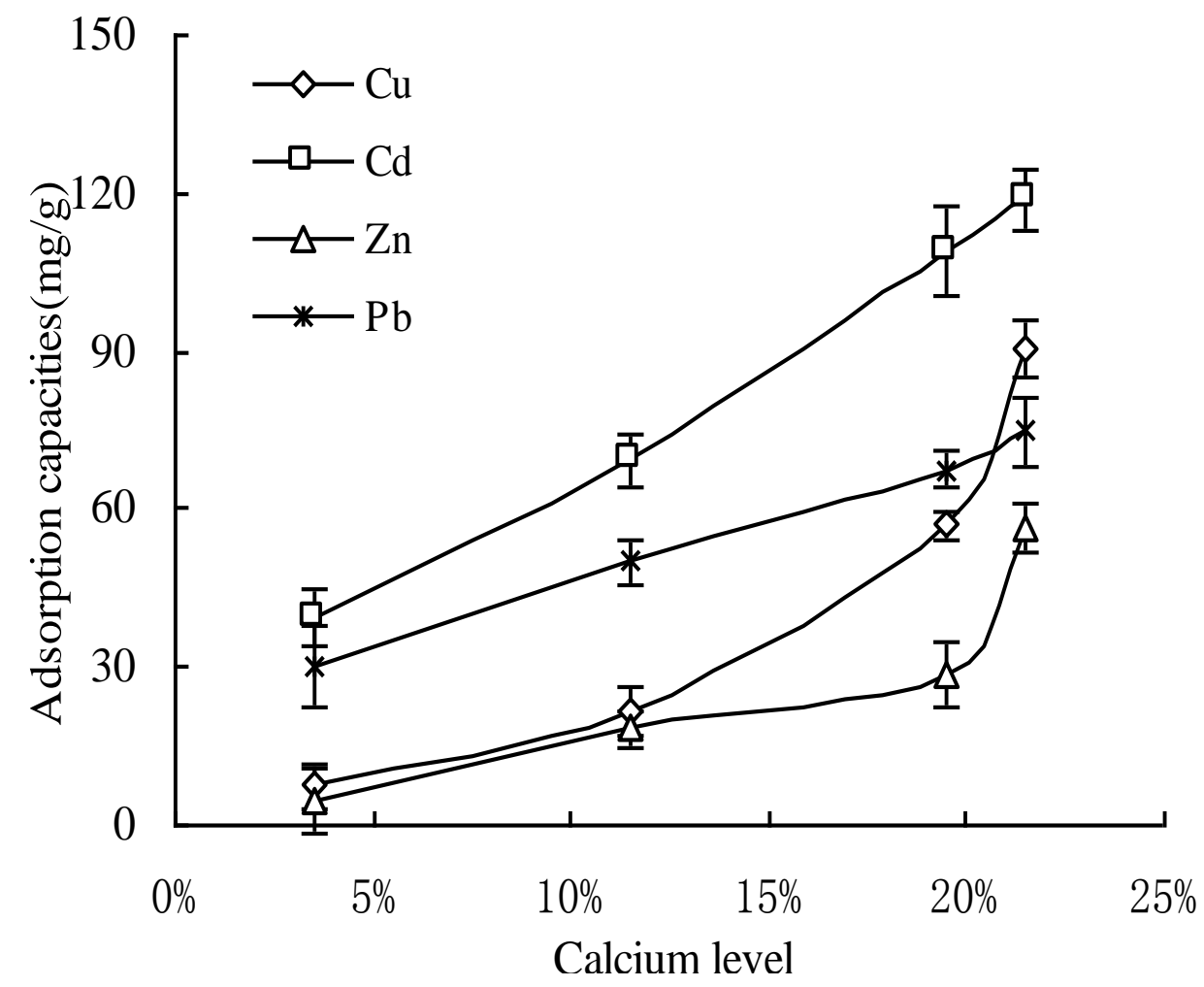

\subsection{Comparison of Adsorption between CCM, Chitin and Chitosan}

In order to study the superiority of crayfish as an absorbent, chitin and two types of chitosan, with different degrees of deacetylation $(70.9 \%$ and $88.6 \%)$, were extracted from the crayfish carapace. Under the same experimental conditions, the adsorption characters of these materials showed significant differences (Figure 9). The adsorption capacity of the crayfish carapace had the maximum value, a value that was much higher than that of the other adsorbents. Chitin had the minimum adsorption capacity and the adsorption capacities of chitosan increased with the degree of deacetylation. The adsorption capacities of chitin and chitosan prepared in this experiment was lower than that of previous literature. The most likely cause was differences in the purity of the samples.

It was noted that crayfish carapace contains multiple components compared with chitosan. In particular, crayfish carapace contained a significant amount of $\mathrm{CaCO}_{3}$, while chitosan, by virtue of its processing, was presumably Ca-free [28]. In addition, crayfish carapace has special mechanical properties by virtue of its structure (as a mineralization product in nature). In this study, the extraction ratios of the chitin, chitosan $\mathrm{A}$, and chitosan $\mathrm{B}$ were $18.40,16.25$ and $15.6 \%$, respectively. Thus, it would be much too expensive to use the chitosan extracted from crayfish carapace as an adsorbent, when the availability and effectiveness of CCM is superior. In previous literature, under certain conditions (initial $\mathrm{pH} 5.0$; amount of adsorbent $1 \mathrm{~g} / \mathrm{L}$; temperature $30{ }^{\circ} \mathrm{C}$; time $24 \mathrm{~h}$ ), the following 
heavy metal removal capacities and removal rates were found: crab carapace (20-40 mesh) > cation exchange resin (16-42 mesh) > zeolite (200-300 mesh) > powdered activated carbon (200-300 mesh) (7-20 mesh) $\geq$ granular activated carbon (12-16 mesh) [29]. As we know, the crab shell is very similar to the crayfish carapace. Hence, this study could indirectly support our point of view that CCM is a satisfactory adsorbent for heavy metal removal.

Figure 9. Adsorption capacities of the four metal ions on different adsorbents (initial metal concentration $=100 \mathrm{ppm}$; agitation speed $=180 \mathrm{rpm}$; equilibrium time $=2 \mathrm{~h}$; temperature $=25^{\circ} \mathrm{C}$; initial $\mathrm{pH}=5.5$; dosage $=1.0 \mathrm{~g} / \mathrm{L}$ ).

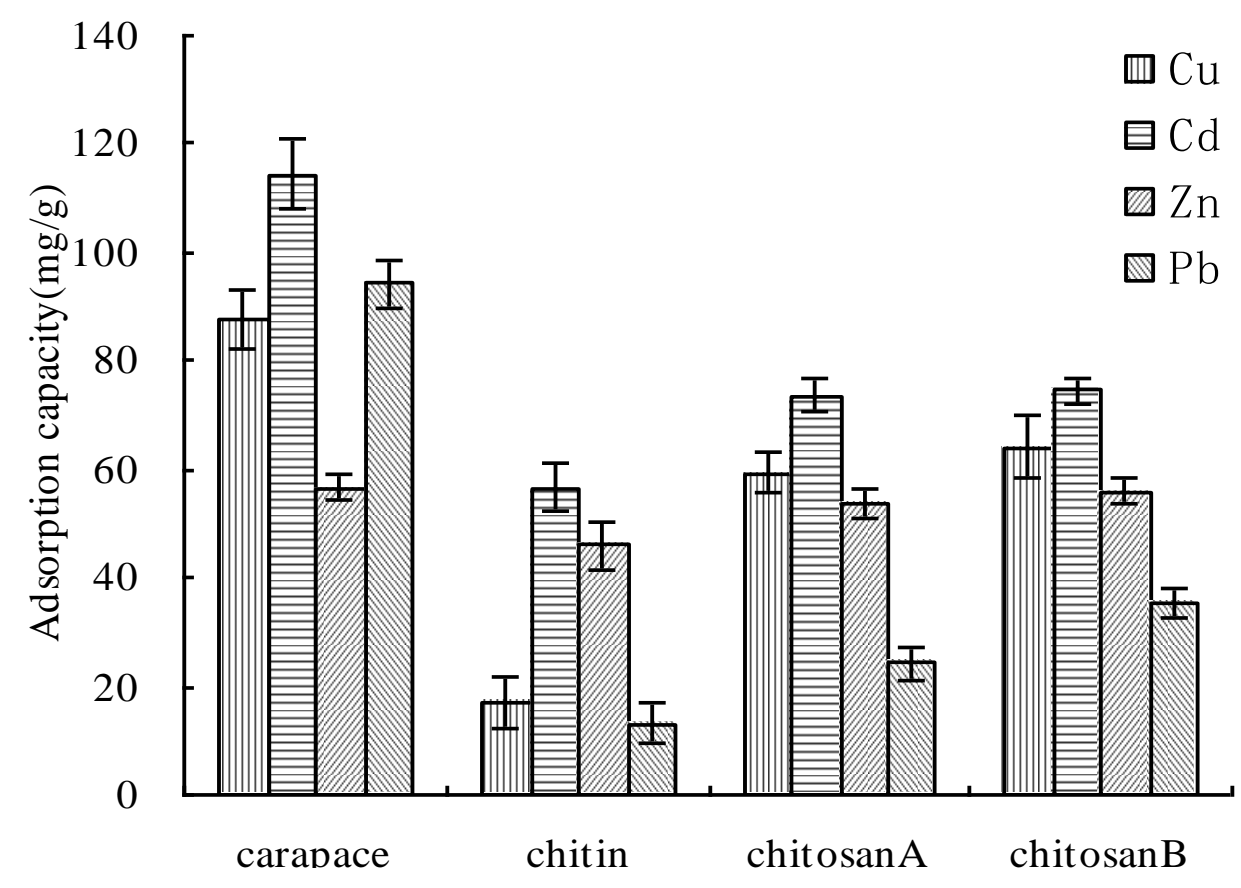

\section{Conclusions}

Heavy metal adsorption by CCM was strongly affected by the $\mathrm{pH}$ of the solution. A neutral $\mathrm{pH}$ value favored the adsorption process. The smaller the particle size, the higher the adsorption capacity recorded. When the particle size was reduced to a certain degree, adsorption capacity did not increase significantly anymore. The adsorption process of copper was exothermal, but the processes of cadmium and zinc were endothermic. Equilibrium times of adsorption for metal ions by CCM were completed within $2 \mathrm{~h}$. The processes of adsorption reaction correspond to the pseudo second-order adsorption equation. The Langmuir equation was able to simulate the adsorption process very well, and the correlation coefficient values $\left(\mathrm{R}^{2}\right)$ all exceeded 0.97 . The adsorption capacities and removal efficiencies of CCM for metal ions were about three-times higher than those of the chitin and chitosan extracted from the CCM. This work indicates that CCM is a practical, effective, and low-cost adsorbent material for the treatment of wastewater streams bearing heavy metal ions.

\section{Acknowledgements}

Contract grant sponsor: National High Technology Research and Development Program of China (863 Program), contract grant number: 2007AA10Z310, 2007AA100408; Support from the 
Program for New Century Excellent Talents in University, contract grant number: NECT-2007073; Support from the Natural Science Funds for Distinguished Young Scholar of Hubei, contract grant number: 2007ABB016.

\section{References}

1. Sun, S.L.; Wang, Q.; Wang, A.Q. Adsorption properties of $\mathrm{Cu}(\mathrm{II})$ ions onto N-succinyl-chitosan and crosslinked N-succinyl-chitosan template resin. Biochem. Eng. J. 2007, 36, 131-138.

2. Integrated Wastewater Discharge Standard GB 8978-1996; Ministry of Environmental Protection: Beijing, China, 1998.

3. Juang, R.S.; Shao, H.J. A simplified equilibrium model for sorption of heavy metal ions from aqueous solutions on chitosan. Water Res. 2002, 36, 2999-3008.

4. Baliley, S.E.; Olin, T.J.; Bricka, R.M.; Adria, D.D. A review of potentially low-cost sorbents for heavy metals. Water Res. 1999, 33, 2469-2479.

5. Mohan, D.; Chander, S. Single component and multi-component adsorption of metal ions by activated carbons. Colloid. Surface. A 2001, 177, 183-196.

6. Guibal, E. Interactions of metal ions with chitosan-based sorbents: A review. Sep. Purif. Technol. 2004, 38, 43-74.

7. Li, N.; Bai, R.B. A novel amine-shielded surface crosslinking of chitosan hydrogel beads for enhanced metal adsorption performance. Ind. Eng. Chem. Res. 2005, 44, 6692-6700.

8. Lee, M.Y.; Hong, K.J.; Kajiuchi, T.; Yang, J.W. Determination of the efficiency and removal mechanism of cobalt by crab carapace particles. J. Chem. Technol. Biot. 2004, 79, 1388-1394.

9. Liu, C.X.; Bai, R.B. Adsorptive removal of copper ions with highly porous chitosan/cellulose acetate blend hollow fiber membranes. J. Membrane Sci. 2006, 284, 313-322.

10. Volesky, B. Advances in biosorption of metals: Selection of biomass types FEMS. Microbiol. Rev. 1994, 14, 291-302

11. Varma, A.J.; Deshpande, S.V.; Kennedy, J.F. Metal complexation by chitosan and its derivatives: A review. Carbohyd. Polym. 2004, 55, 77-93.

12. Rodde, R.H.; Einbu, A.; Varum, K.M. A seasonal study of the chemical composition and chitin quality of shrimp shells obtained from northern shrimp (Pandalus borealis). Carbohyd. Polym. 2008, 71, 388-393.

13. Ehrlich, H.; Koutsoukos, P.G.; Demadis, K.D.; Pokrovsky, O.S. Principles of demineralization: Modern strategies for the isolation of organic frameworks. Part II. Decalcification. Micron 2009, 40, 169-193.

14. Shittu, T.A.; Badmus, B.A. Statistical correlations between mineral element composition, product information and retail price of powdered cocoa beverages in Nigeria. J. Food Compos. Anal. 2009, 22, 212-217.

15. Vijayaraghavan, K.; Palanivelu, K.; Velan, M. Biosorption of copper(II) and cobalt(II) from aqueous solutions by crab carapace particles. Bioresource Technol. 2006, 97, 1411-1419.

16. Pradhan, S.; Shukla, S.S.; Dorris, K.L. Removal of nickel from aqueous solutions using crab carapaces. J. Hazard. Mater. 2005, 125, 201-204. 
17. Wan Ngah, W.S.; Kamari, A.; Koay, Y.J. Equilibrium and kinetics studies of adsorption of copper(II) on chitosan and chitosan/PVA beads. Int. J. Biol. Macromol. 2004, 34, 155-161.

18. Sun, S.L.; Wang, A.Q. Adsorption kinetics of $\mathrm{Cu}(\mathrm{II})$ ions using N, O-carboxymethyl-chitosan. J. Hazard. Mater. 2006, 131, 103-111.

19. Rosa, S.; Laranjeira, C.M.; Riela, H.G.; Favere, V.T. Cross-linked quaternary chitosan as an adsorbent for the removal of the reactive dye from aqueous solutions. J. Hazard. Mater. 2008, 155, 253-260.

20. Rojasa, G.; Silvaa, J.; Floresb, J.A.; Rodriguezb, A.L.; Lyc, M.; Maldonadob, H. Adsorption of chromium onto cross-linked chitosan. Sep. Purif. Technol. 2005, 44, 31-36.

21. Qi, L.F.; Xu, Z.R. Lead sorption from aqueous solutions on chitosan nanoparticles. Colloid. Surface. A 2004, 251, 183-190.

22. Lu, S.G.; Gibb, S.W.; Cochrane, E. Effective removal of zinc ions from aqueous solutions using crab carapace biosorbent. J. Hazard. Mater. 2007, 149, 208-217.

23. Yuan, Y.C.; Zhu, Z.S.; Zhang, Q.M. Mechanism study of adsorbtion $\mathrm{Co}^{2+}$ on cross-linked chitosan. Ion. Exch. Adsorpt. 2005, 21, 452-460.

24. Vasconcelos, H.L.; Camargo, T.P.; Gonffcalves, N.S.; Neves, A.; Laranjeira, C.M.; Favere, V.T. Chitosan crosslinked with a metal complexing agent: Synthesis, characterization and copper(II) ions adsorption. React. Funct. Polym. 2008, 68, 572-579.

25. Vieira, R.S.; Guibal, E.; Silva, E.A.; Beppu, M.M. Adsorption and desorption of binary mixtures of copper and mercury ions on natural and cross-linked chitosan membranes. Adsorption 2007, 13, 603-611.

26. Wan Ngah, W.S.; Ghani, S.A.; Kamari, A. Adsorption behaviour of Fe(II) and Fe(III) ions in aqueous solution on chitosan and cross-linked chitosan beads. Bioresource Technol. 2005, 96, 443-450.

27. Tong, H.; Yao, S.N. Study on micro-morphology and structure of crab and crayfish shell. J. Anal. Sci. 1997, 13, 206-209.

28. Tudor, E.A.; Gryte, C.C.; Harris, C. Seashell: Detoxifying agents for metal contamination waters. Water Air Soil Pollut. 2006, 173, 209-242.

29. An, H.K.; Park, B.Y.; Kim, D.S. Crab shell for the removal of heavy metals from aqueous solution. Water Res. 2001, 35, 3551-3556.

(C) 2010 by the authors; licensee MDPI, Basel, Switzerland. This article is an Open Access article distributed under the terms and conditions of the Creative Commons Attribution license (http://creativecommons.org/licenses/by/3.0/). 